\title{
Competing MYB networks as switches in primary and secondary metabolism in spruce
}

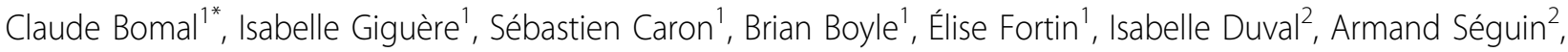 \\ John MacKay ${ }^{1}$ \\ From IUFRO Tree Biotechnology Conference 2011: From Genomes to Integration and Delivery \\ Arraial d Ajuda, Bahia, Brazil. 26 June - 2 July 2011
}

\section{Background}

R2R3-MYB transcription factors are regulatory genes that have been linked to key aspects of plant development and secondary metabolism. They have been implicated in the transcriptional control of phenylpropanoid, and flavonoid metabolic pathways in model plant systems. However, in trees, knowledge is still limited about the role of R2R3-MYBs in such processes. Microarray transcript profiles (9K custom cDNA array) obtained from comparison between wild type and transgenic spruces that constitutively overexpressed Pinus taeda MYB1, MYB8 [1], and MYB14 [2] identified putative targets in flavonoid and phenylpropanoid metabolism. Cross-comparison of these data sets identified 70 sequences that were common to the three transgenic backgrounds: interestingly, 66 of these 70 sequences were co-expressed between PtMYB1 and PtMYB8 transgenics but produced opposite profiles with PtMYB14 transgenics. Pairwise comparisons between these transgenic data sets identified 121 additional sequences showing opposite profiles. Predicted annotations and KEGG classification showed that many of the sequences were linked to the metabolism of amino acids and carbohydrates as well as flavonoids, phenylpropanoids, and terpenoids.It was hypothesized that MYB1/MYB8 and MYB14 may be part of competing transcriptional networks for the regulation of primary metabolism and secondary metabolism. The opposite transcriptional responses might also support structural or defensive oriented response, respectively.

\footnotetext{
* Correspondence: Claude.Bomal@sbf.ulaval.ca

'Centre d'Étude de la Forêt, Université Laval, Québec (QC), GIV A06, Canada
} Full list of author information is available at the end of the article

\section{Material and methods}

A qPCR based experimental approach was used to test these hypotheses by evaluating transcript profile of the negatively co-expressed sequences together with MYB1, MYB8 and MYB14. Transcript levels were monitored during a diurnal cycle in three year-old wild type spruces, based on the fact that some genes associated to phenylpropanoid metabolism [3] and stress [4] were reported to follow a diurnal transcript variation. Our analysis also included a set of 10 additional MYBs putatively linked to secondary cell wall deposition [1] and stress oriented response [2]. A Spearman correlation rank test was used to estimate significant correlation (adjusted $P$ val $\leq 0.01$, FDR 1\%) between MYB transcript profiles and selected co-expressed sequences. A functional assay system developed in embryogenic spruce cells was used to screen for possible interactions between transcription factors and promoters of putative target genes.

\section{Results}

Among the co-expressed sequences tested, five sequences coding for 4CL, DHS2, OMT1, SMT4, and a Lipase thioesterase displayed transcript profile that positively correlated with those of PgMYB1, PgMYB8 but negatively with those of PgMYB14 and PgMYB15, the closest homologue of PgMYB14 [2]. Interestingly, these oppositions were observed in secondary xylem differentiating tissues but not in bark/phloem. Significant correlations were also observed between the co-expressed sequences tested and the others MYBs. A separate analysis of large scale expression profiles for spruce transcription factors gave some additional evidences that these putative competing MYB networks may be tissue-preferential. Transient expression results obtained with our functional assay system further suggested interactions between these 
MYBs and some of their proposed targets. More extensive testing is in working progress.

\section{Conclusions}

The results of the present study strongly suggest that putative MYB networks may compete to allow rapid metabolic switch within wood forming tissue in order to direct metabolic flux towards specific aspects of primary and secondary metabolism for structural, or defensiveoriented response.

\section{Author details}

'Centre d'Étude de la Forêt, Université Laval, Québec (QC), G1V A06, Canada.

${ }^{2}$ Natural Resources Canada, Canadian Forest Service, Laurentian Forestry

Centre, Québec (QC), G1V A06, Canada.

Published: 13 September 2011

\section{References}

1. Bomal C, Bedon F, Caron S, Mansfield SD, Levasseur C, Cooke JEK, Blais S,

Tremblay L, Morency MJ, Pavy N, Grima-Pettenati J, Séguin A, MacKay J:

Involvement of Pinus taeda MYB1 and MYB8 in phenylpropanoid

metabolism and secondary cell wall biogenesis: a comparative in planta analysis. J Exp Bot 2008, 59:3925-3939.

2. Bedon F, Bomal C, Caron S, Levasseur C, Boyle B, Mansfield SD, Schmidt A Gershenzon J, Grima-Pettenati J, Séguin A, Mackay J: Subgroup 4 R2R3MYBs in conifer trees: gene family expansion and contribution to the isoprenoid- and flavonoidoriented responses. J Exp Bot 2010, 61:3847-3864.

3. Harmer SL, Hogenesch JB, Straume M, Chang HS, Han B, Zhu T, Wang X, Kreps JA, Kay SA: Orchestrated transcription of key pathways in Arabidopsis by the circadian clock. Science 2000, 290:2110-2113.

4. Walley JW, Coughlan S, Hudson ME, Covington MF, Kaspi R, Banu G, Harmer SL, Dehesh K: Mechanical stress induces biotic and abiotic stress responses via a novel cis-element. PLOS Genet 2007, 3:e172.

doi:10.1186/1753-6561-5-S7-P63

Cite this article as: Bomal et al:: Competing MYB networks as switches in primary and secondary metabolism in spruce. BMC Proceedings 20115 (Suppl 7):P63.

\section{Submit your next manuscript to BioMed Central} and take full advantage of:

- Convenient online submission

- Thorough peer review

- No space constraints or color figure charges

- Immediate publication on acceptance

- Inclusion in PubMed, CAS, Scopus and Google Scholar

- Research which is freely available for redistribution

Submit your manuscript at www.biomedcentral.com/submit 